\title{
Effects of Temperature on Partial Discharges and Streamers in an Ester Liquid under AC Stress
}

DOI:

10.1109/TDEI.2019.008131

\section{Document Version}

Accepted author manuscript

Link to publication record in Manchester Research Explorer

\section{Citation for published version (APA):}

Huang, Y., Liu, Q., \& Wang, Z. (2019). Effects of Temperature on Partial Discharges and Streamers in an Ester Liquid under AC Stress. I E E E Transactions on Dielectrics and Electrical Insulation.

https://doi.org/10.1109/TDEI.2019.008131

\section{Published in:}

I E E E Transactions on Dielectrics and Electrical Insulation

\section{Citing this paper}

Please note that where the full-text provided on Manchester Research Explorer is the Author Accepted Manuscript or Proof version this may differ from the final Published version. If citing, it is advised that you check and use the publisher's definitive version.

\section{General rights}

Copyright and moral rights for the publications made accessible in the Research Explorer are retained by the authors and/or other copyright owners and it is a condition of accessing publications that users recognise and abide by the legal requirements associated with these rights.

\section{Takedown policy}

If you believe that this document breaches copyright please refer to the University of Manchester's Takedown Procedures [http://man.ac.uk/04Y6Bo] or contact uml.scholarlycommunications@manchester.ac.uk providing relevant details, so we can investigate your claim.

\section{OPEN ACCESS}




\title{
Effects of Temperature on Partial Discharges and Streamers in an Ester Liquid under AC Stress
}

\author{
Y.M. Huang, Q. Liu and Z.D. Wang \\ School of Electrical and Electronic Engineering \\ The University of Manchester \\ Manchester M13 9PL, UK
}

\begin{abstract}
Insulating liquids in transformers experience the transformer operational temperature rather than the ambient temperature that is often used in discharge studies in laboratories. This paper presents the effects of temperature on partial discharge (PD) and streamer characteristics of a synthetic ester liquid under AC stress. A needle-toplane electrode configuration was employed to perform the PD and streamer measurements. The PD pattern, streamer images, current signals were chosen to explore the PD and streamer characteristics at temperatures of $20,40,60$ and $80{ }^{\circ} \mathrm{C}$. It was found that both PD and streamer characteristics of the synthetic ester are temperature dependent. As the temperature increased, the magnitude and repetition rate of positive PDs increased slightly, but both the magnitude and repetition rate of negative PDs dropped dramatically. In addition, it was observed that when the temperature increased, the stopping length of positive streamers did not change appreciably while a significant reduction of negative streamer length and area was witnessed. A mechanism based on the electrohydrodynamics (EHD) phenomenon and the space charge theory has been used to explain the different effects of temperature on positive and negative PDs.
\end{abstract}

Index Terms - ester liquid, partial discharge (PD), streamer, electrohydrodynamics (EHD), transformer, temperature

\section{INTRODUCTION}

POWER transformers play an extremely important role in power networks. Their failures could result in a significant risk to the power network and a high cost for recovery. Hence, it is of great significance to ensure their reliable operations. At present, the liquid/solid combined insulation system is widely used in power transformers. During the practical operation, the insulation system is under multi-stresses and degraded gradually overtime, which could increase the risk of partial discharge (PD) and threaten the safe operation of power transformers.

Up to now, the pre-breakdown phenomenon in transformer liquids has been extensively studied [1-9], and a large portion of the research has been carried out to better understand the partial discharge phenomenon under AC stress. Concerning this subject, research efforts can generally be categorized into streamer investigation and PD patterns. The former is more concerned on the physical nature of partial discharges while the latter is more related to the industry application [1].

Manuscript received on 8 March 2019, in final form 21 May 2019, accepted xx Month 20yy. Corresponding author: Q. Liu.
Previous studies have shown that the PD and streamer characteristics of insulating liquids are meaningfully influenced by many different factors such as moisture, floating particles, ageing and so on [2, 3, 8, 9]. It was reported that applying high AC electric fields with needle to plane electrode would produce space charges around the needle tip and cause the movement of the insulating liquid, which is also known as the electrohydrodynamics (EHD) [10]. Previous research has revealed that the space charges play a significant role on the PD activities at higher PD rates and applied voltages [11]. In addition, space charges generated in the previous $\mathrm{AC}$ half cycle would affect the electric field distribution close to the needle tip and further influence the initiation of PDs in the following half cycle [12-14]. Nevertheless, most of these studies were carried out at room temperature. In practice, the insulating liquids are not only used as the insulation material but also act as the coolant to dissipate the heat generated by the windings in power transformers. Meanwhile, due to the operating condition, the transformer oil is generally working at an elevated temperature rather than the ambient temperature.

As for the effect of temperature on the pre-breakdown phenomenon in insulating liquids, only very limited efforts were paid [15-17]. PD characteristics in the transformer oil at 
various temperatures under the uniform AC stress with different defects were studied in [15]. It was found that the increasing temperature could improve the PDIV and result in a lower $\mathrm{PD}$ magnitude and $\mathrm{PD}$ repetition rate. $\mathrm{PD}$ and breakdown voltages in a biodegradable oil at different temperatures were investigated in [16]. As the temperature increased, both the PDIV and the breakdown voltage increased. The effect of temperature on PD characteristics in the moving transformer oil contaminated by metallic particles was studied under uniform AC stress [17]. The PD magnitude and frequency first increased and then decreased when the temperature was increased from 40 to $80^{\circ} \mathrm{C}$.

In the power transformer industry, the mineral oil has been widely used for decades based on its low cost, excellent dielectric strength and good cooling performance. However, as a petroleum-based product, the mineral oil also has its limitations in terms of high flammability and low degradability. With the development of the transformer industry, the concerns of environmental impacts have become more and more important. To answer these concerns, the ester liquids have become a promising alternative of the conventional mineral oil due to its higher fire point and lower environmental impact [18]. With the increasing application of ester liquids in large power transformers, it is essential to have a comprehensive understanding of its dielectric behaviors including PD and streamer characteristics at different temperatures.

In this study, the PD and streamers characteristics of a synthetic ester liquid have been experimentally investigated at different temperatures under various applied voltages. The PD pattern, PD magnitude and PD repetition rate were characterised while the streamer stopping length, streamer area and discharge current were also presented for further analysis. Then, discussions were carried out in terms of the space charge distribution at different temperatures in order to explain the experimental results.

\section{EXPERIMENTAL DESCRIPTIONS}

As shown in Figure 1, the experimental setup was basically composed of three parts: high voltage supply unit, oil heating/circulation system and measurement unit.

The oil heating/circulation system mainly consisted of a buffer chamber, a needle valve, a test cell, a flow meter and a centrifugal pump. The stainless steel made buffer chamber with a volume of $20 \mathrm{~L}$ was grounded for charge relaxation. A heating tape was wrapped on the chamber for the heating function. The pump was used to force the oil to circulate in the system and the needle valve could help to control the oil flow rate. The circulation direction is shown in Figure 1 and the flow rate was obtained from the flow meter.

During the heating process, the oil flow rate was controlled below $1 \mathrm{~L} / \mathrm{min}$. Hence, the oil could stay in the buffer chamber for more than $20 \mathrm{mins}$ before flowing into the test cell again, which is long enough for extra charges to dissipate. Thus, the effect of streaming electrification could be ignored. Two thermocouples were placed at the entrance and exit of test cell to indicate the temperature inside the cell. The pump was switched off after the temperature in the test cell reached the desired value, and a one-minute standby was implemented to ensure all the formal tests were carried out in a static oil condition. The test cell was made of Nylon and had two transparent Perspex windows for the streamer observation.

In this study, the needle-to-plane electrode configuration was employed to generate a local high electric field for the PD and streamer initiation. The needle tip had a radius of around $10 \mu \mathrm{m}$, and the gap distance between the needle tip and the plane electrode was fixed at $25 \mathrm{~mm}$. The plane electrode was made of copper and had a diameter of $50 \mathrm{~mm}$.

The arrangement of the high voltage supply unit and the measurement unit was based on the standard IEC 60270 [19]. The power supply was an AC transformer which could provide up to $70 \mathrm{kV}$ (all the voltage levels are RMS values in this paper). A $1 \mathrm{M} \Omega$ water current-limit resistor was connected between the test cell and the high voltage supply to limit the current arc during the breakdowns. In order to record the applied voltage across the test cell, a capacitive high voltage divider was connected in parallel with the test cell and the voltage signal was obtained from an oscilloscope.

A commercial PD detector Omicron MPD 600 was connected in series with a $500 \mathrm{pF}$ coupling capacitor to perform the PD measurement. The IEC 60270 mode of the detector was used, where the centre frequency is $250 \mathrm{kHz}$ and bandwidth is in the range of 100 to $400 \mathrm{kHz}$. The data obtained from the detector was further processed to obtain maximum PD magnitude and repetition rate by using a selfdeveloped MATLAB code. The noise level was controlled below $10 \mathrm{pC}$, and hence $20 \mathrm{pC}$ was selected as the threshold for valid PD signals. To obtain the corresponding current signal, a low-inductance $50 \Omega$ resistor was connected in series with the plane electrode.

In order to capture the streamer image, a high-speed camera and the shadowgraph technique were used. Once the current signal detected from the measurement resistor was recorded by the oscilloscope, a TTL signal would be sent to the camera simultaneously. Then the camera would be triggered to capture the corresponding images. In this study, the camera was working in a central trigger mode, which enabled the camera to continuously record a certain number of frames before and after the initiation of a streamer.

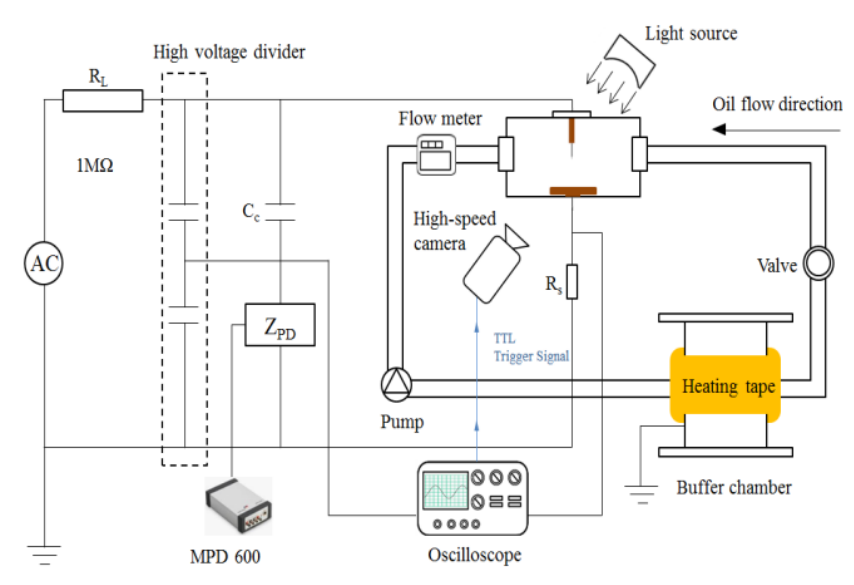

Figure 1. Experimental setup. 
In this paper, the tested oil sample was a synthetic ester liquid: MIDEL 7131. The oil samples were directly taken from the sealed barrel without further filtering. The particle content was measured and the contamination level was defined as 'Nil' according to [20]. Before the formal test, all the oil samples were degassed and dehydrated at $85^{\circ} \mathrm{C}$ in a vacuum oven below $500 \mathrm{~Pa}$ for 72 hours. After the process, the relative humidity of the liquid was below $10 \%$.

The test temperature was ranged from 20 to $80{ }^{\circ} \mathrm{C}$ with a step of $20^{\circ} \mathrm{C}$. For the PD measurement, the applied voltage was maintained for 1 minute for each recording. Every PD measurement was performed for three times to observe repeatability. To avoid potential changes of the needle tip, a new needle would be used when the applied voltage was changed to another level. In other words, each needle was only used for three PD measurements. Ten streamers were captured under each applied voltage level at the four different temperatures.

\section{RESULTS}

\subsection{PDIV AND TYPICAL PD PATTERN}

The PD inception voltage (PDIV) at different temperatures was determined according to the procedure detailed in our previous study [21]. The threshold for determining the PDIV was taken as $20 \mathrm{pC}$. Table 1 summaries the PDIV and standard deviation (SD) at different temperatures. It is shown that the PDIVs at the four temperatures are very close to each other, with an average of $12.7 \mathrm{kV}$. In other words, it means temperature does not affect the observed PDIVs in this study.

Table 1. PDIVs at different temperatures, $\mathrm{kV}$.

\begin{tabular}{ccccc}
\hline Temperature & $20^{\circ} \mathrm{C}$ & $40^{\circ} \mathrm{C}$ & $60{ }^{\circ} \mathrm{C}$ & $80^{\circ} \mathrm{C}$ \\
\hline PDIV & 12.7 & 12.8 & 12.4 & 12.9 \\
SD & 0.21 & 0.22 & 0.16 & 0.26 \\
\hline
\end{tabular}

PD patterns under voltages above the PDIV were investigated at various temperatures. The applied voltage was increased step by step from 16 to $26 \mathrm{kV}$ with a step of $2 \mathrm{kV}$. The maximum applied voltage for 60 and $80{ }^{\circ} \mathrm{C}$ was set to only $24 \mathrm{kV}$ as breakdowns might occur during the PD measurement at a higher voltage. Typical PD patterns at different temperatures under $24 \mathrm{kV}$ are shown in Figure 2. It is noted that the peak magnitude of positive and negative PDs generally occurred around the vicinity of the peaks of the applied voltage waveform. What is important is that the increased temperature resulted in a flatter and more compressed PD pattern in the negative half voltage cycle, especially when the temperature was raised from 20 to $40{ }^{\circ} \mathrm{C}$. Moreover, from 40 to $80{ }^{\circ} \mathrm{C}$, no further evident change of negative PD patterns was observed.

\subsection{PD CHARACTERISTICS}

Figure 3 and Figure 4 show the PD magnitude of positive PDs (those occurring in the positive half cycle) and negative PDs (those occurring in the negative half cycle) under different voltages at different temperatures. By increasing the applied voltage, both the positive and negative PD magnitude increased continuously at the same temperature level. As for the impact of temperature on the PD magnitude, it was found that the increased temperature gradually induced a higher positive PD magnitude under the same voltage level, and this influence was more obvious under higher applied voltages. However, the negative PD magnitude decreased substantially with the increasing temperature.

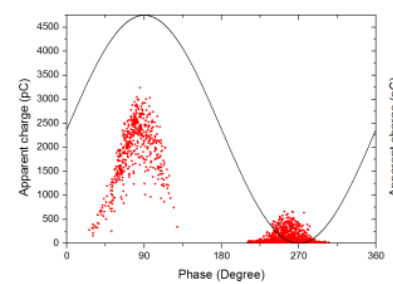

$20{ }^{\circ} \mathrm{C}$

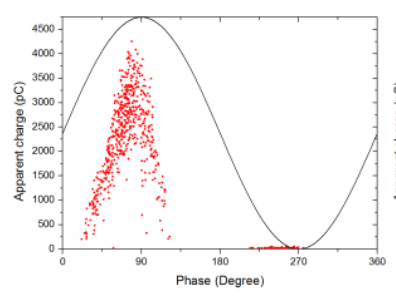

$60{ }^{\circ} \mathrm{C}$

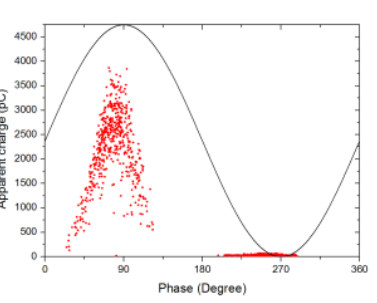

$40^{\circ} \mathrm{C}$

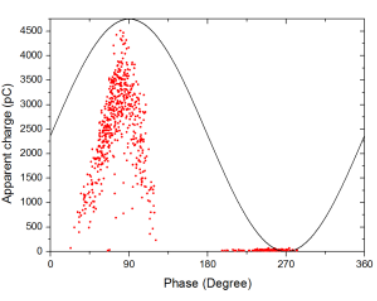

$80{ }^{\circ} \mathrm{C}$
Figure 2. Typical PD patterns at four temperatures under $24 \mathrm{kV}$.

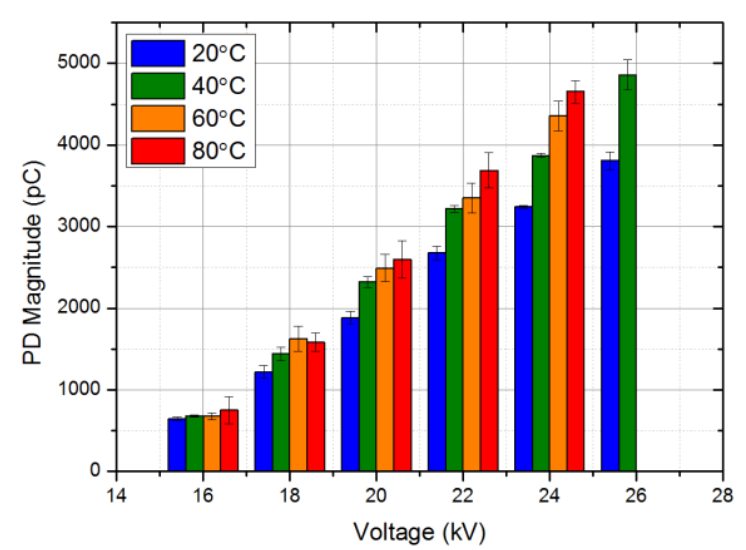

Figure 3. Positive PD magnitude under various voltages at different temperatures.

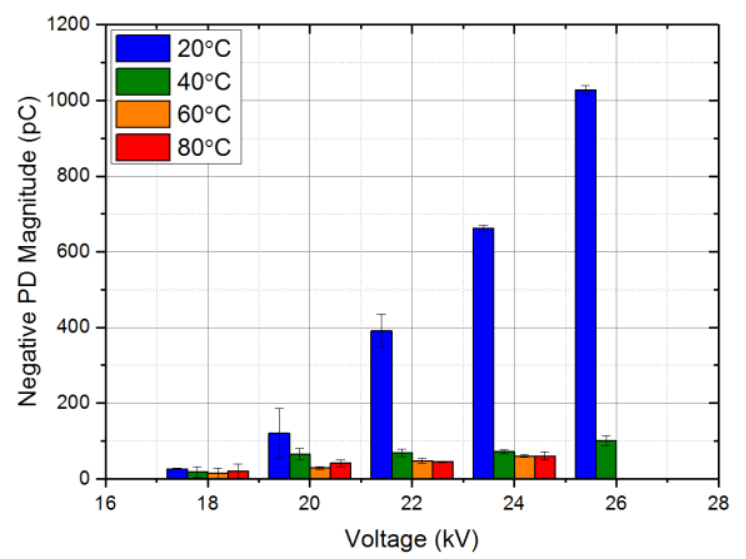

Figure 4. Negative PD magnitude under various voltages at different temperatures.

The total number of PDs occurring in one minute is defined as the PD repetition rate. The variations of the total PD 
repetition rate and corresponding frequency (in $\mathrm{Hz}$ ) under different voltages at various temperatures are presented in Figure 5. At the same temperature level, the total PD repetition rate was continuously increased with the applied voltage. From 16 to $20 \mathrm{kV}$, the effect of temperature on the $\mathrm{PD}$ repetition rate was not obvious. However, along with the applied voltage increased from 22 to $26 \mathrm{kV}$, it was interesting to witness a dramatic reduction of the total PD repetition rate caused by the rise of temperature.

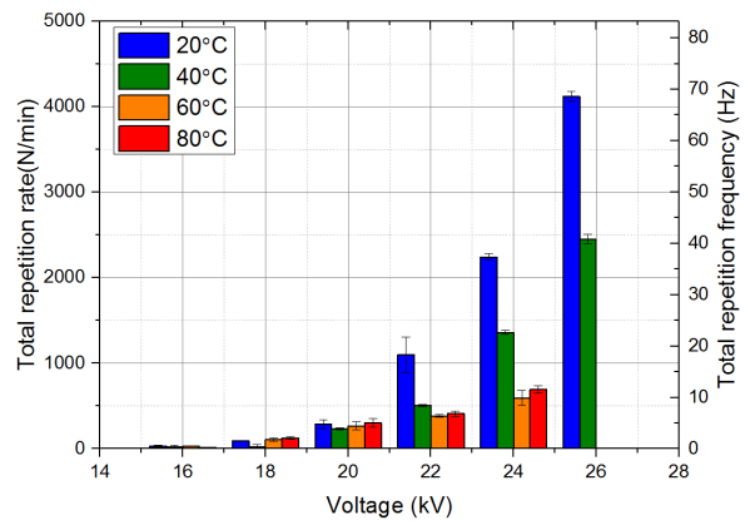

Figure 5. Total repetition rate and frequency under different voltages at different temperatures.

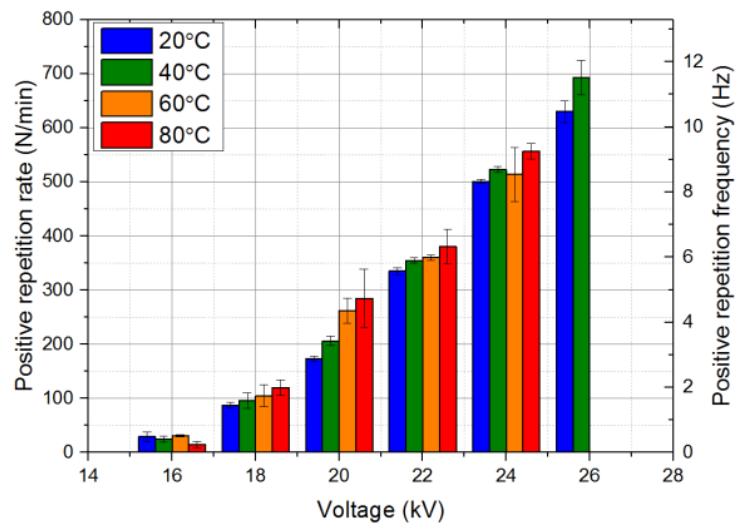

(a)

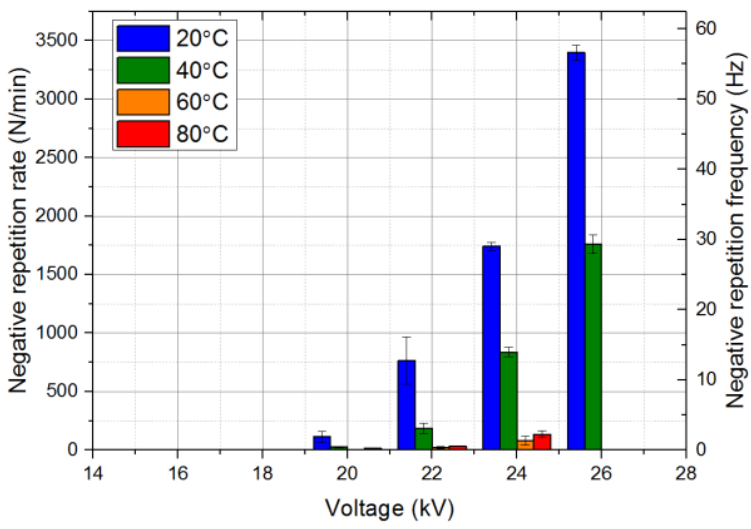

(b)

Figure 6. PD repetition rate and frequency under different voltages at different temperatures of (a) positive PDs and (b) negative PDs.

To further investigate the large reduction of the total repetition rate resulted from the increasing temperature, the repetition rate of positive and negative PDs, are presented in
Figure $6 a$ and Figure $6 b$, respectively. From Figure $6 a$, the positive $\mathrm{PD}$ repetition rate increased slightly with the increasing temperature. On the other hand, Figure $6 \mathrm{~b}$ indicates that the negative $\mathrm{PD}$ repetition rate dropped substantially when the temperature was raised from 20 to $80{ }^{\circ} \mathrm{C}$. The slight increment of positive PD repetition rate could not offset the dramatic drop of the negative PD repetition rate, which resulted in the eventual decrease of the total $\mathrm{PD}$ repetition rate at a higher temperature shown in Figure 5.

\subsection{STREAMER CHARACTERISTICS}

The same as the PD measurement, the maximum applied voltage of streamer investigations was only $24 \mathrm{kV}$ for $60^{\circ} \mathrm{C}$ and $80{ }^{\circ} \mathrm{C}$ to prevent breakdowns during the streamer measurement. The stopping length, propagation velocity and streamer area were used to study the characteristics of streamers under various conditions. In this paper, the stopping length is defined as the straight distance from the needle tip to the furthest streamer tip. The streamer propagation time is defined as the duration of corresponding current signals.

Typical shapes of positive streamers (those occurred during the positive half AC cycle) under various applied voltages at different temperatures are shown in Figure 7. It can be seen that by increasing the voltage, the positive streamer propagated further, and with more main branches. Meanwhile, under the same voltage level, the number of branches was decreased with the increase of temperature.

The stopping length of positive streamers under various voltages at different temperatures is summarized in Figure 8. It is indicated that the stopping length increased with applied voltage but the effect of temperature on the stopping length was no obvious. Only under 24 and $26 \mathrm{kV}$, a slight increase of stopping length with increasing temperature was noticeable.

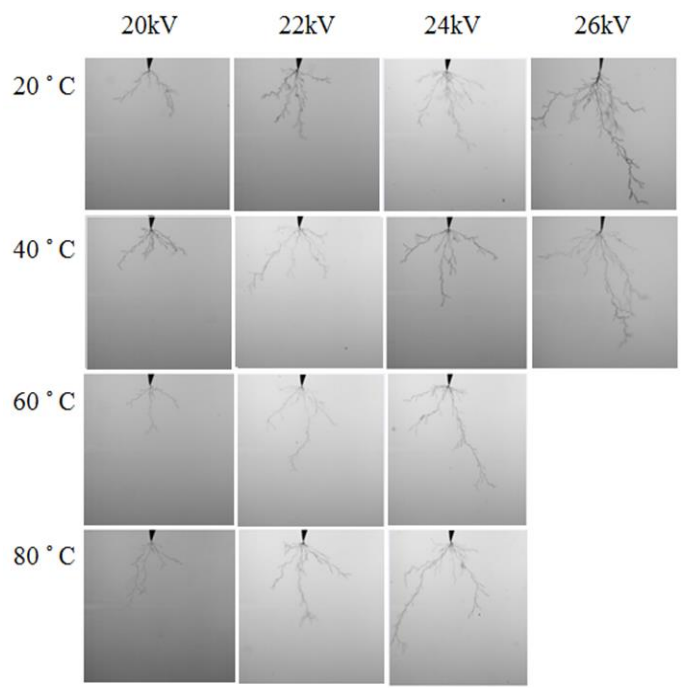

Figure 7. Typical positive streamers under different voltages at different temperatures.

The average propagation velocity of the streamer was calculated as the ratio between the stopping length and the duration measured from the current signal. Figure 9 compares the average streamer propagation velocity of positive streamers under different voltages at various temperatures. It was revealed that the average propagation velocity was around 
$1.5 \mathrm{~km} / \mathrm{s}$ which is classified as the 2nd mode streamer [22]. The average propagation velocity remained stable in the investigated range of the applied voltage at different temperatures.

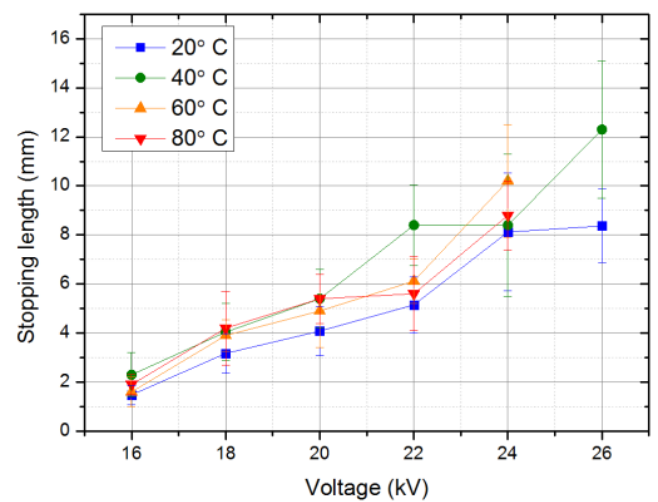

Figure 8. The stopping length of positive streamers under different voltages at various temperatures.

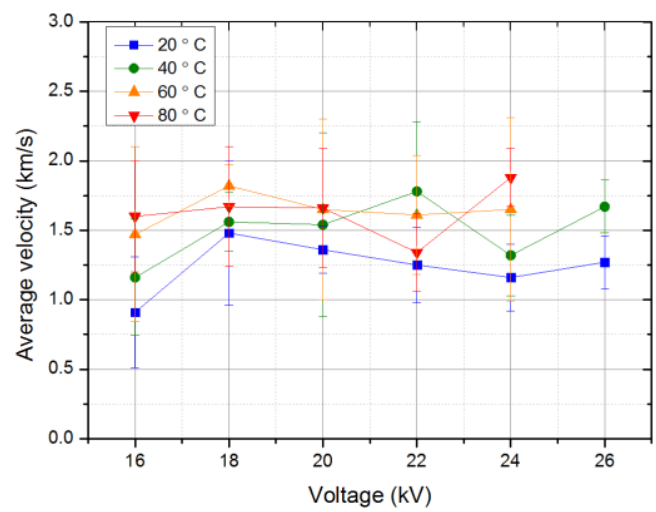

Figure 9. The average propagation velocity of positive streamers under different voltages at various temperatures.

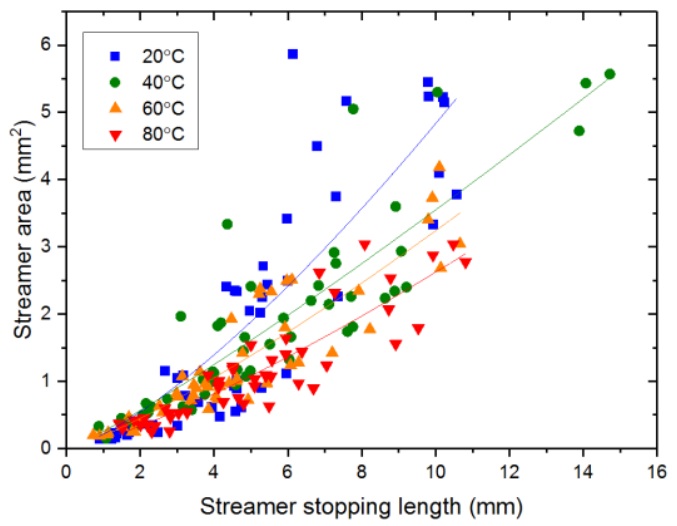

Figure 10. Comparison of streamer areas at various temperatures.

The area of streamers was measured by a self-developed MATLAB code which could convert the streamer image to a binary image and count the total number of pixels which were covered by all streamer branches. Figure 10 shows the relationship between the average stopping length and the average streamer area at different temperatures. The shape and branch characteristics of streamers can be studied by comparing the area of streamers with the same stopping length. According to Figure 10, it can be concluded that positive streamers at lower temperature level tend to have a larger streamer area or more branches compared to those at a higher temperature.

Typical negative streamers (those occurred during the negative half $\mathrm{AC}$ cycle) under various voltage levels with increasing temperature are presented in Figure 11 . At $20{ }^{\circ} \mathrm{C}$, the rising voltage generally resulted in a longer stopping length and more branches of the negative streamer. However, from 40 to $80{ }^{\circ} \mathrm{C}$, negative streamers became much smaller compared to those at $20{ }^{\circ} \mathrm{C}$ and no obvious shape change was observed with the increase of applied voltages.

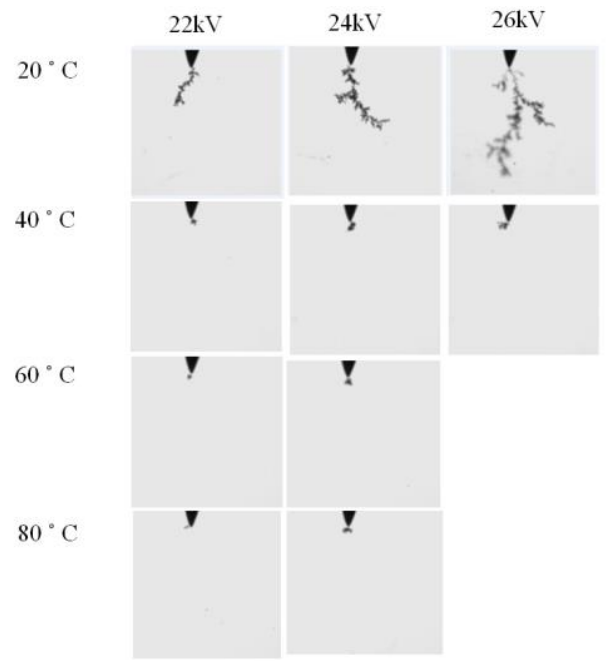

Figure 11. Typical negative streamers under different voltages at various temperatures.

Considering the fact that negative streamers at higher temperatures were too small for the accurate measurement of stopping lengths, the streamer area was used to evaluate the effect of temperature on negative streamers and the results are summarized in Figure 12. As the temperature was increased from 20 to $40{ }^{\circ} \mathrm{C}$, a sharp decrease of the streamer area was observed while the decreasing tendency became less evident when the temperature was further increased from 40 to $80^{\circ} \mathrm{C}$. This trend is in accord with previous results that the rising temperature decreases the negative PD magnitude shown in Figure 4.

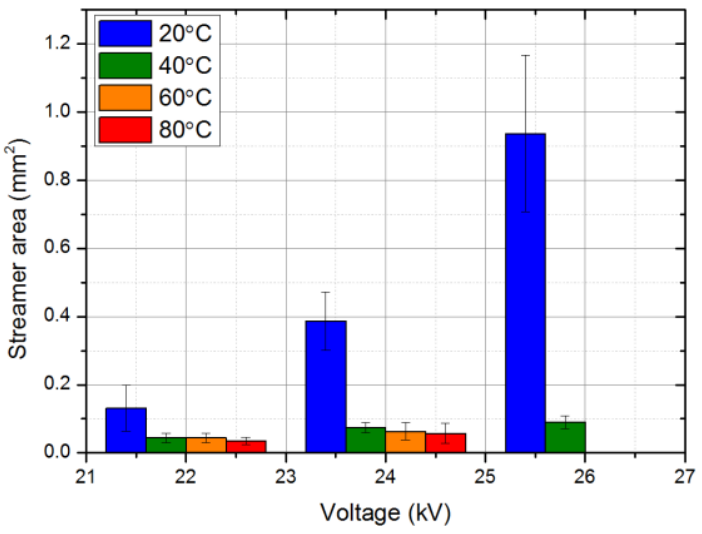

Figure 12. The negative streamer areas under different voltages at various temperatures. 
The reduction impact of temperature on the negative streamer area can also be evidenced by studying the measured negative discharge current signals. Four typical current signals of negative streamers under $24 \mathrm{kV}$ at different temperatures are presented in Figure 13. The negative streamer current signal was composed of a train of high-frequency discrete pulses with an increasing magnitude at $20{ }^{\circ} \mathrm{C}$. As the temperature was increased, it was revealed that the peak value of the negative current was reduced significantly. In addition, the total number of pulses of a negative PD current signal also decreased when the temperature was raised.
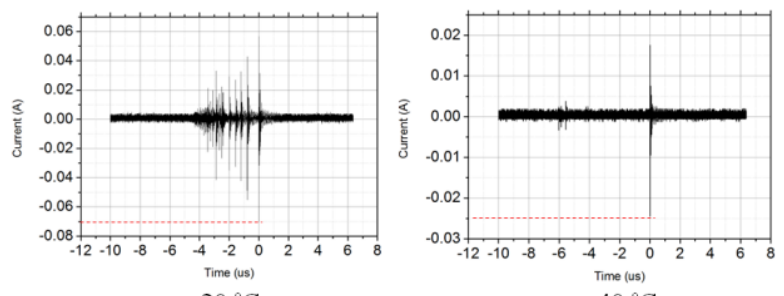

$20^{\circ} \mathrm{C}$

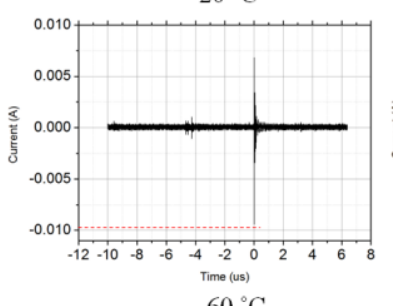

$40^{\circ} \mathrm{C}$

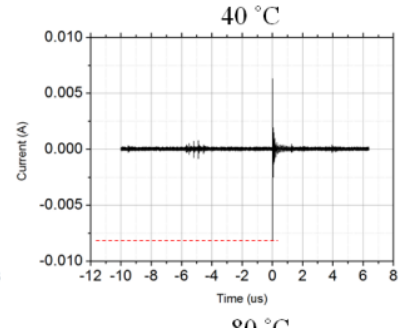

Figure 13. Typical negative current signals under $24 \mathrm{kV}$ at different temperatures.

\section{DISCUSSION}

\subsection{SPACE CHARGE EFFECT ON STREAMERS IN ONE AC VOLTAGE CYCLE}

Under AC stress, more than one streamer may occur in the same AC cycle. For these successive streamers that happening closely in time, the preceding streamer could leave some 'byproduct' for subsequent streamers. These 'by-product' could be either charges or gaseous channels or both. Before the occurrence of the subsequent streamer, the residual charges or gaseous channels may not have enough time to be dissipated. As a result, the electrical field around the needle tip could be distorted and further affect the initiation and propagation of subsequent streamers.

It was observed that a positive streamer occurring close to $90^{\circ}$ was generally followed by a negative streamer occurring close to $270^{\circ}$, which agrees with previous findings about correlations between positive and negative PDs [13]. Figure 14 presents a pair of typical positive and negative streamers that occurring in one voltage cycle at four different temperatures under $24 \mathrm{kV}$. Their corresponding phase angles are also indicated. According to Figure 14a, the two streamers occurred close to the positive and negative voltage peaks respectively. Based on the space charge theory, after the occurrence of the positive streamer, some positive charges were left around the needle tip. Then, after the applied voltage of the needle tip was reversed to negative, the electric field between the needle tip and the positive charges was enhanced, which promoted the initiation and propagation of the subsequent negative streamer.

However, as shown in Figure $14 \mathrm{~b}, \mathrm{c}$ and $\mathrm{d}$, at higher temperatures, the stopping length of the subsequent negatives were significantly decreased compared to the negative streamer in Figure 14a. It can be concluded that the space charge effect from the proceeding positive streamer to facilitate the successive negative streamer was reduced owing to the increase of temperature.

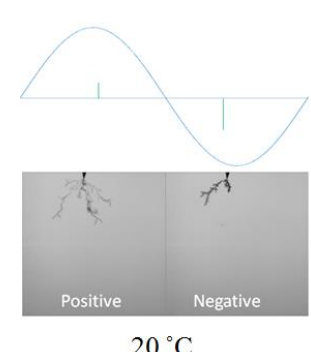

(a)

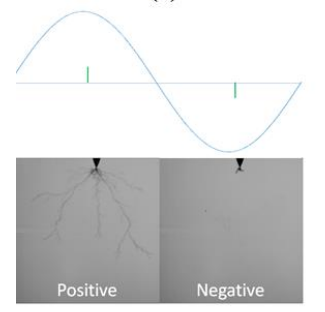

$60{ }^{\circ} \mathrm{C}$

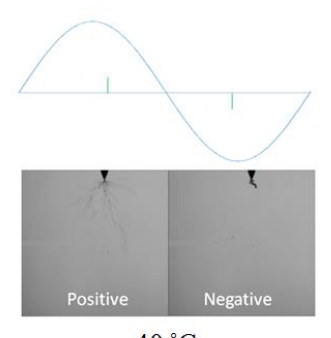

$40{ }^{\circ} \mathrm{C}$

(b)

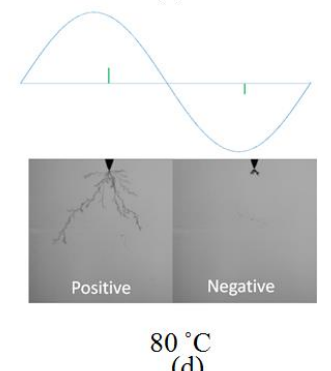

(d)
Figure 14. Space charge effect on negative streamers at different temperatures (a) $20^{\circ} \mathrm{C}$, (b) $40^{\circ} \mathrm{C}$, (c) $60^{\circ} \mathrm{C}$, (d) $80^{\circ} \mathrm{C}$.

\subsection{STREAMER DISSIPATION PROCESS UNDER AC STRESS}

With the help of the high-speed camera, the dissipation process of the positive streamer can be clearly observed. The investigation of the dissipation process can help us to have a better understanding of the space charge distribution and dissipation around the needle tip. Figure 15 presents a typical positive streamer dissipation process at $20{ }^{\circ} \mathrm{C}$ under $24 \mathrm{kV}$. It is shown that, when the positive streamer began to dissipate, the branches of the streamer would expand and fade in a very short time. In addition, instead of dissipating around the needle tip, the 'root' of the streamer was pushed away from the needle tip and moved forwards to the plane electrode. After $10 \mathrm{~ms}$ from the occurrence of the positive streamer, before the 'black' channels were totally dissipated, the subsequent negative streamer occurred. As the 'black' channels were the results from the change of the density in the liquid [23], the movement of the channels could indicate the local movement of the liquid around the needle tip under AC stress, which is also known as the EHD phenomenon [10].

By tracking the trajectories of the 'black' channels, the velocity of the corresponding liquid movement can be estimated. Figure 16 summarizes the instantaneous distance from the moving 'root' of the positive streamer to the needle tip at different temperatures under $24 \mathrm{kV}$ during the 
dissipation process. Ten streamers were analyzed at each temperature. According to Figure 16, the liquid flowing velocity close to the needle tip (within $2 \mathrm{~mm}$ ) was about 0.4 $\mathrm{m} / \mathrm{s}$. It did not change with the increase of temperature probably because electric field is dominating the liquid movement in this region. Nevertheless, in the areas further away from the needle tip, the rising temperature resulted in an increased liquid velocity, especially when the temperature was increased from 20 to $40{ }^{\circ} \mathrm{C}$. This may be caused by the decrease of the viscosity of MIDEL 7131 when the temperature was increased from 20 to $80{ }^{\circ} \mathrm{C}$ [24]. The viscosity of MIDEL 7131 dropped dramatically when the temperature increased from 20 to $40{ }^{\circ} \mathrm{C}$, and then the decreasing trend became much slower when the temperature was further increased to $80^{\circ} \mathrm{C}$. The nonlinear reduction of the viscosity with increasing temperature agreed with the change of liquid flowing velocity indicated in Figure 16.

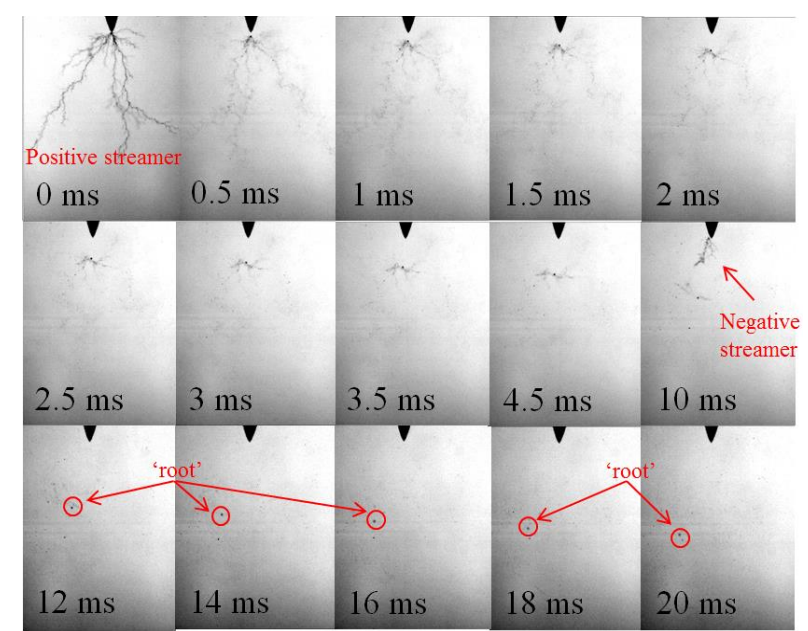

Figure 15. Typical dissipation process of a positive streamer under $24 \mathrm{kV}$ at $20^{\circ} \mathrm{C}$.

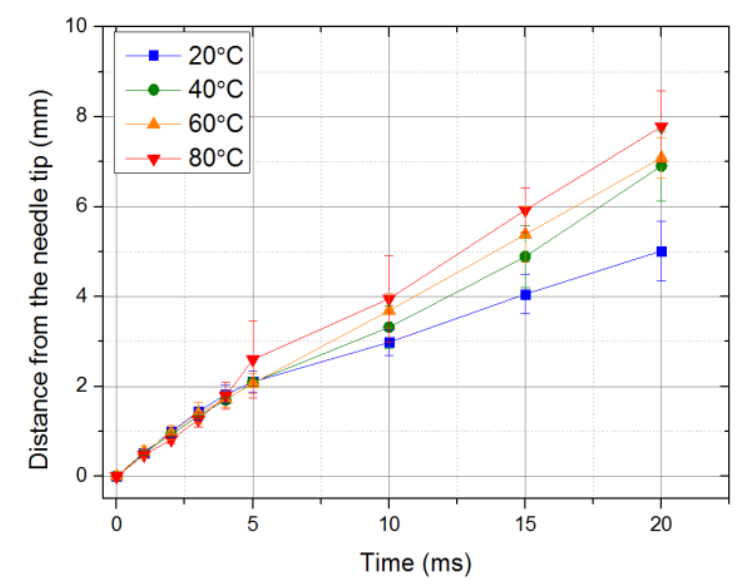

Figure 16. The moving distance from the 'root' to the needle tip with time at different temperatures.

\subsection{ASSUMPTION OF SPACE CHARGE} DISTRIBUTION AT DIFFERENT TEMPERATURES

Based on previous discussions and available literatures, an assumption of space charge distribution at different temperatures was made to explain the effects of temperature on PD and streamer characteristics. As reported in previous studies [11-13, 25], charge injection from the needle electrode and ionic dissociation in the liquid contribute to space charge phenomena in the liquid. Under the positive half cycle, as the mobility of electrons is much higher than that of positive charges, some positive charges are left close to the needle tip while most electrons have been attracted by the needle electrode and neutralized. It is assumed that those residual positive charges will move towards the plane electrode with the oil flow resulted from the EHD phenomenon, while the effect of liquid motion on electrons is ignored considering their high mobility.

Figure 17 is a conceptual sketch to show how the temperature influences the space charge distribution and further affect the PD and streamers under AC stress. As shown in Figure 17a, at the low temperature level, under the positive half cycle, the homocharges around the needle tip reduce the internal electric field. Hence, it becomes more difficult for the successive positive streamer to occur and propagate. When the polarity of the needle tip is reversed to negative, these heterocharges enhance the internal electrical field, Esc, and promote the initiation and propagation of negative streamers.

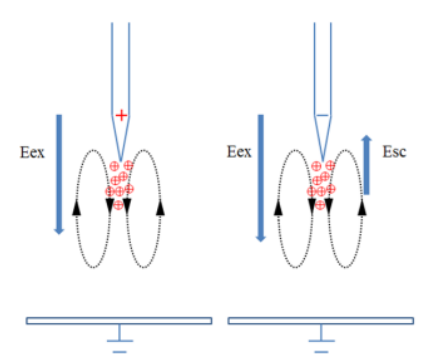

(a)

Low temperature

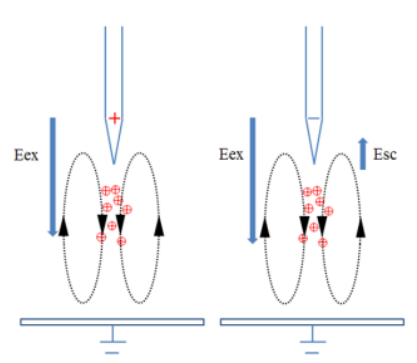

(b)
Figure 17. Sketch showing the influence of temperature on the space charge distribution under AC stress.

As shown in Figure 17b, when the temperature is increased, the significant drop of the liquid viscosity enhances the EHD motion and those residual positive charges move further from the needle tip before the next streamer occurs. As a result, the space charge distribution is changed and the negative effect of the homocharges on following positive streamers is weakened. Therefore, it becomes more likely for subsequent positive streamers to initiate, and the magnitude and repetition rate of positive PDs increase correspondingly, which are supported by Figure 3 and Figure $6 a$. On the other hand, under the negative half cycle, the enhancement of the internal electric resulted from the heterocharges is decreased, which makes it more difficult for negative streamers to occur and propagate. In addition, the magnitude and repetition rate of negative PDs decrease consequently, which are supported by Figure 4 and Figure 6b.

\section{CONCLUSIONS}

In this paper, the effects of temperature on partial discharges and streamers in a synthetic ester were experimentally studied. It was found that the increased temperature increases the magnitude and repetition rate of positive PDs. In contrast, the rise of the temperature had a greater opposite impact on 
negative PDs. Both the magnitude and repetition rate of negative PDs dropped dramatically with the increasing temperature. These influences were also verified by the investigation of streamers at different temperatures. It was also observed that the increasing temperature increases the liquid flowing velocity around the needle tip due to the decreasing viscosity of the liquid. An assumption based on the space charge theory was made to explain the different effects of temperature on positive and negative PDs.

\section{REFERENCES}

[1] Z. Liu, Q. Liu, and Z. Wang, "Effect of electric field configuration on streamer and partial discharge phenomena in a hydrocarbon insulating liquid under AC stress," J. Phys.D: Appl. Phys., vol. 49, no. 18, p. $185501,2016$.

[2] W. Lu and Q. Liu, "Effect of cellulose particles on impulse breakdown in ester transformer liquids in uniform electric fields," IEEE Trans. Dielectr. Electr. Insul., vol. 22, no. 5, pp. 2554-2564, 2015.

[3] S. Ingebrigtsen, L. Lundgaard, and P. Astrand, "Effects of additives on prebreakdown phenomena in liquid cyclohexane: II. Streamer propagation," J. Phys. D: Appl. Phys., vol. 40, no. 18, p. 5624, 2007.

[4] Q. Liu and Z. Wang, "Breakdown and withstand strengths of ester transformer liquids in a quasi-uniform field under impulse voltages," IEEE Trans. Dielectr. Electr. Insul., vol. 20, no. 2, pp. 571-579, 2013.

[5] Q. Liu and Z. Wang, "Streamer characteristic and breakdown in synthetic and natural ester transformer liquids with pressboard interface under lightning impulse voltage," IEEE Trans. Dielectr. Electr. Insul., vol. 18, no. 6, 2011.

[6] Q. Liu and Z. Wang, "Secondary reverse streamer observed in an ester insulating liquid under negative impulse voltage," J. Phys. D: Appl. Phys., vol. 44, no. 40, p. 405203, 2011.

[7] M. Krins, H. Borsi, and E. Gockenbach, "Influence of carbon particles on the breakdown and partial discharge inception voltage of aged mineral based transformer oil," IEEE Int. Conf. Dielectr. Mat. Meas. Appl., 1996, pp. 251-254.

[8] D. Bolliger and S. Boggs, "Partial discharge based diagnostics for impurities in insulating fluid," IEEE Trans. Dielectr. Electr. Insul., vol. 20, no. 5, pp. 1659-1668, 2013.

[9] Z. Liu et al., "Partial discharge behaviour of transformer liquids and the influence of moisture content," IEEE Int. Conf. Dielectr. Liquids (ICDL), 2014, pp. 1-4.

[10] P. Atten, "Electrohydrodynamic instability and motion induced by injected space charge in insulating liquids," IEEE Trans. Dielectr. Electr. Insul., vol. 3, no. 1, pp. 1-17, 1996.

[11] L. Lundgaard and O. Lesaint, "Discharges in liquids in point-plane gap under ac and impulse stress," Annu. Rep. Conf. Electr. Insul. Dielectr. Phenom. (CEIDP), 1995, pp. 596-599.

[12] T. Grav and L. E. Lundgaard, "Currents in AC stressed liquid insulated needle plane gap," IEEE Int. Conf. Dielectr. Liquids (ICDL), 2014, pp. $1-5$.

[13] T. Grav and L. E. Lundgaard, "PD occurrence in liquids in ac stressed needle plane gap," IEEE Int. Conf. Dielectr. Liquids (ICDL), 2014, pp. $1-5$.

[14] H. Borsi, E. Gockenbach, U. Schröder, and G. Schiller, "Contribution to the clarification of partial discharge behaviour in insulating liquids using the schlieren technique," European Transactions on Electrical Power, vol. 1, no. 5, pp. 271-279, 1991.

[15] S. Li, B. Gao, and G. Wu, "Influences of oil flow speed and temperature on partial discharge properties in transformer oil," Australasian Universities Power Engineering Conference (AUPEC), 2016, pp. 1-4.

[16] H. Sutikno, "Effects of temperature on the breakdown voltage and partial discharge patterns of biodegradable oil," IEEE Int. Conf. Electr. Ing. Informatics (ICEEI), 2011, pp. 1-6.

[17] C. Pan, J. Tang, Y. Zhang, X. Luo, and X. Li, "Variation of discharge characteristics with temperature in moving transformer oil contaminated by metallic particles," IEEE Access, vol. 6, pp. 4005040058, 2018.

[18] R. Asano and S. A. Page, "Reducing environmental impact and improving safety and performance of power transformers with natural ester dielectric insulating fluids," IEEE Trans. Ind. Appl., vol. 50, no. 1, pp. 134-141, 2014.

[19] High-voltage test techniques: partial discharge measurements, IEC60270, 2000.

[20] T. CIGRE, "Effect of particles on transformer dielectric strength ", Brochure 157, Paris, France, 2000.

[21] Z. Liu, J. Park, and Q. Liu, "Partial discharge inception voltages of an inhibited mineral oil in quasi-uniform electric fields," IEEE Int. Conf. Prop. Appl. Dielectr. Mat. (ICPADM), 2015, pp. 420-423.

[22] O. Lesaint and G. Massala, "Positive streamer propagation in large oil gaps: experimental characterization of propagation modes," IEEE Trans. Dielectr. Electr. Insul., vol. 5, no. 3, pp. 360-370, 1998.

[23] O. Lesaint and R. Tobazeon, "Streamer generation and propagation in transformer oil under ac divergent field conditions," IEEE Trans. Electr. Insul., vol. 23, no. 6, pp. 941-954, 1988.

[24] X. Zhang, Z. Wang, Q. Liu, P. Jarman, A. Gyore, and P. Dyer, "Numerical investigation of influences of coolant types on flow distribution and pressure drop in disc type transformer windings," IEEE Int. Conf. Cond. Mon. Diagnostics (ICDMD), 2016, pp. 52-55.

[25] K. Wu, Q. Zhu, H. Wang, X. Wang, and S. Li, "Space charge behavior in the sample with two layers of oil-immersed-paper and oil," IEEE Trans. Dielectr. Electr. Insul., vol. 21, no. 4, pp. 1857-1865, 2014.

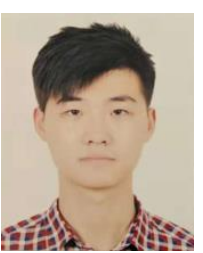

Yiming Huang obtained the B.Sc degree in electrical and electronic engineering (2012) from the North China Electric Power University and the M.Sc. degree in electrical and electronic engineering (2015) from the University of Manchester, UK. He is currently a Ph.D. degree student at the Electrical Energy and Power Systems Group in the School of Electrical and Electronic Engineering at The University of Manchester. His research interests are partial discharge, creepage discharge and streaming electrification.

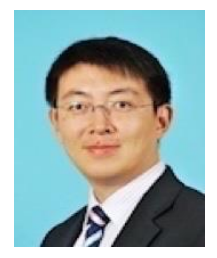

Qiang Liu (S'08-M'12-SM'18) obtained the B.Eng. degree in electrical engineering (2005) and the M.Eng. degree in high voltage and electrical insulation (2008) from Xi'an Jiaotong University in China, and the Ph.D. degree in electrical power engineering (2011) from The University of Manchester in UK. Currently he is a Senior Lecturer in the Power and Energy Division in the School of Electrical and Electronic Engineering at The University of Manchester. His research interests are on pre-breakdown and breakdown phenomena in liquids, alternative transformer liquids, streaming electrification, ageing of insulating materials, thermal modelling, transformer asset management and high voltage testing.

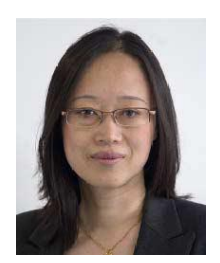

Zhongdong Wang received the BSc and the MSc degrees in high voltage engineering from Tsinghua University in 1991 and 1993 and the $\mathrm{PhD}$ degree in electrical engineering from UMIST in 1999. Currently she is a Professor of High Voltage Engineering of the School of Electrical and Electronic Engineering at The University of Manchester. Her research interests focus on power transformers covering all aspects of modelling and simulation, materials \& systems, and asset management policies. 